\title{
Uterine artery Doppler indices: pulsatility index and resistance index as predictive tools for the incidence of heavy menstrual bleeding related to copper intrauterine contraceptive device
}

\author{
Alaa Mohamed Attia, MD, Mohammed El-Husseiny Radwan, MD, Yousef Abo Elwan, MD, \\ Hend Salah Abdo Saleh, MD \\ Department of Obstetrics and Gynecology, Faculty of Medicine, Zagazig University, Zagazig, Egypt
}

\begin{abstract}
Objectives
To assess the predictive value of the initial uterine artery Doppler indices, the pulsatility index (PI), and resistance index (RI) in the prediction of heavy menstrual bleeding before and after copper intrauterine contraceptive device (IUCD) insertion.
\end{abstract}

\section{Methods}

The current prospective clinical study included 100 women who intended to use a copper IUCD (CU T-380A) and met the inclusion criteria. Uterine artery Doppler PI and RI indices were calculated before IUCD insertion and at three and six months after insertion. Based on the presence or absence of menorrhagia, all women were classified into two groups: non-bleeding $(n=52)$ and extreme menstrual bleeding $(n=48)$. Receiver operating curve analysis was used to determine the predictive value of uterine artery $\mathrm{PI}$ and $\mathrm{RI}$ in patients with menorrhagia relevant to IUCD.

\section{Results}

The PI and RI indices displayed a highly significant difference between the IUCD groups at three and six months after insertion $(P<0.001)$. Uterine artery $\mathrm{PI} \leq 2.02$ (sensitivity of $95.8 \%$, specificity of $100 \%$, and area below the curve [AUC] of 0.97 at $P$-value $<0.001$ ) and RI $\leq 0.83$ (sensitivity of $93.8 \%$, specificity of $100 \%$, and AUC of 0.949 at $P$-value $<0.001$ ) were correlated with significant menstrual bleeding following insertion of IUCD.

\section{Conclusion}

The presented results confirmed our assumption that the initial studies of uterine artery Doppler can predict heavymenstrual bleeding associated with IUCD and therefore, should be conducted in women pursuing reversible longacting contraception.

Keywords: Copper intrauterine contraceptive device; Transvaginal Doppler ultrasound; Pulsatility index and resistance index

\section{Introduction}

Intrauterine contraceptive device (IUCD) is a common family planning contraceptive method used worldwide [1]. Importantly, the copper intrauterine devices (Cu-IUDs), with very low failure rates of between $0.2 \%$ to $1.0 \%$, are most commonly used for long-acting, reversible contraception (LARC). Owing to its low failure rate and long lifetime, CU-T380A is preferred $[2,3]$.
Received: 2020.11.13. Revised: 2021.02.03. Accepted: 2021.02.25. Corresponding author: Alaa Mohamed Attia, MD Department of Obstetrics and Gynecology, Zagazig University Hospital, Koliat Al TOB St, Shaibet an Nakareyah, Zagazig, Ash Sharqia Governorate 44519, Egypt E-mail: alaaattia2103@gmail.com https://orcid.org/0000-0002-2233-7806

Articles published in Obstet Gynecol Sci are open-access, distributed under the terms of the Creative Commons Attribution Non-Commercial License (http://creativecommons. org/licenses/by-nc/3.0/) which permits unrestricted non-commercial use, distribution, and reproduction in any medium, provided the original work is properly cited.

Copyright $\odot 2021$ Korean Society of Obstetrics and Gynecology 


\title{
Obstetrics \& Gynecology Science
}

\author{
Vol. 64, No. 3, 2021
}

The most common adverse effects associated with IUCD use are abnormal uterine bleeding, pelvic pain, and dysmenorrhea (about $30-50 \%$ ). Approximately $10-20 \%$ of users requesting IUCD removal during their first year of use [4]. Many women are affected by premature discontinuation. Approximately 40 million women per year have IUCD inserted. Of these, 5-15\% discontinue IUCD due to bleeding or discomfort within the first year of use. Cu-T380A is a nonhormone contraceptive device based on the release of copper ions that are spermicidal. However, the device may induce an inflammatory response resulting in a hostile uterine environment [5].

The Doppler uterine artery indices the pulsatility index (PI), and resistance index (RI) have been widely researched to establish the association between heavy menstrual hemorrhage associated with IUCD and increased blood flow in the uterine artery $[5,6]$. Doppler analysis of the uterine artery was performed before and three and six months after IUCD insertion in this study. The main objective of the current study was to predict the occurrence of the above-mentioned side effects prior to IUCD insertion through uterine artery Doppler blood flow analysis and to explore its impact on the uterine artery Doppler flow characteristics in situ.

\section{Materials and methods}

In the current prospective clinical trial, 100 women who wanted to use copper IUCD (CU-T380A) and fulfilled the inclusion criteria were recruited from the family planning clinic at the Obstetrics and Gynecology Department of Zagazig University Hospitals, in collaboration with the Radiology Department of Zagazig General Hospitals, Zagazig City, Sharika Governorate, Egypt, over eight months from April 2019 to January 2020.

\section{Inclusion criteria}

The inclusion criteria were as follows: young women aged 20-40 years old who desired long-acting contraception; normal menstrual bleeding cycles (24-35 days); and no hormonal treatment for at least three months before IUCD insertion.

\section{Exclusion criteria}

The exclusion criteria were as follows: pregnancy; undiagnosed uterine bleeding or hormonal contraceptive pills in the three months preceding; previous genital infection; a bulky uterus with ultrasonographic proof of ovarian, uterine, or endometrial disorders such as uterine myoma, adenomyosis, endometrial polyps, ovarian cysts uterine anomaly, uterine fibroids, PID, or septic abortion; and physiological menorrhagia.

\section{Methodology}

After obtaining the patient's consent to participate in the study, all women were subjected to the following:

Careful pelvic examination to identify uterine size and position.

IUCD insertion: insertion of CU-T380A should be performed postmenstrual or 6 th weeks postpartum under obstetrics and gynecologists' supervision.

Transvaginal ultrasonography (TVUS): An ultrasound device (GE Logiq P7 device with a 7,5 MHz curved transvaginal transducer) was used for a 2-D mode real-time sonographic analysis to measure the uterine length and width, as well as the correct position of the IUCD inside the uterine cavity. Endometrial thickness was also identified by measuring the distance between the two basal layers of the anterior and posterior uterine walls in $\mathrm{mm}$.

Transvaginal pulsed Doppler on the uterine artery (TVPD): After taking uterine measurements, the mode was shifted to color Doppler and the uterine arteries were located less than $2 \mathrm{~cm}$ from the vaginal fornices at the level of the interior os. The Doppler color was switched on in the 2D mode. The right and left uterine arteries were identified. Then, the mode was switched to pulsed Doppler, and the velocity waveforms of the blood flow were displayed. The image was then frozen with at least three waveform signals. Subsequently, the $\mathrm{PI}$ and RI for both uterine arteries were calculated.

TVUS and TVPD were performed on women at the time of Cu-IUCD insertion and the three- and six-month follow-up. All ultrasound examinations were performed on the fourth or fifth day of the menstrual cycle. At the second visit, all women were divided into two groups based on the presence or absence of menorrhagia (menorrhagia is menstrual bleeding of more than $80 \mathrm{~mL}$ per cycle).

Group 1 (52 cases): cases without complaint of menorrhagia.

Group 2 (48 cases): cases with a complaint of menorrhagia. 


\section{Obstetrics \& Gynecology Science}

Alaa Mohamed Attia, et al. Uterine artery Doppler

\section{Statistical analysis}

The obtained data were tabulated, and statistical analyses were performed using the Social Sciences Statistical Package 2018 (SPSS version 20.0; IBM Corp., Armonk, NY, USA). All data are presented as mean \pm standard deviation, median, range, and qualitative data are presented as absolute frequencies (number) and relative frequencies (\%).

\section{Results}

As presented in Table 1, we found a non-significant difference in the age and parity between the two groups at three and six months after IUCD insertion. The mean age of all participants in group (1), which included patients without complaint of menorrhagia, was $28.01 \pm 5.51(20-40)$ years and their mean parity was $2.04 \pm 1.13$ (1-5). In group (2), which included patients who complained about menorrhagia, the mean age was $28.43 \pm 5.86(20-39)$ years and their mean parity was $2.08 \pm 1.02(1-5)$.

This study showed that there is a highly significant relationship between heavy menstrual bleeding associated with IUCD insertion and Doppler indices of the uterine artery (RI and PI) before IUCD insertion and at three and six months post-insertion. Low uterine artery PI and RI were observed in women with menorrhagia (group [2]) at baseline and three and six months after IUCD insertion, relative to the normal non-bleeding group (1) $(P<0.05)$, as shown in Tables 2 and 3, respectively.

Multiple regression analyses of participant characteristics and heavy menstrual bleeding-related to IUCD showed that the pulsatility index of the uterine artery ( $\mathrm{PI} \leq 2.02$ ) was consistent with menorrhagia following insertion of IUCD (sensitivity $95.8 \%$ [85.7-99.5] and specificity 100\% [93.2-100]), with an AUC of $0.971(0.916-0.994)$ at $P<0.001$. Additionally, the resistance index of the uterine artery $(R I \leq 0.83)$ was also correlated with heavy menstrual bleeding after IUCD insertion (sensitivity 93.8\%, specificity 100\%, AUC 0.949, P<0.001), as presented in Table 4 . These were revealed in the receiver operating characteristic (ROC) curve of PI (Fig. 1A) and RI (Fig. 1B) of the uterine artery indices.

Fig. 2 and 3 show the PI and RI values of the uterine artery in the bleeding group, at baseline and three months after insertion. Fig. 4 shows the average indices in the non-bleeding group, three months after insertion.

\section{Discussion}

Worldwide, approximately $14.3 \%$ of women of reproductive

Table 1. Relationship between demographic data and heavy menstrual bleeding associated with IUCD

\begin{tabular}{|c|c|c|c|c|}
\hline \multirow{2}{*}{ Basic charactertics } & \multicolumn{2}{|c|}{ Heavy menstrual bleeding associated with IUCD } & \multirow{2}{*}{ Test } & \multirow{2}{*}{$P$-value (Sig. } \\
\hline & Absent $(n=52)$ & Present $(n=48)$ & & \\
\hline \multicolumn{5}{|l|}{ Age (years) } \\
\hline Mean \pm SD & $28.01 \pm 5.51$ & $28.43 \pm 5.86$ & $-0.308^{a)}$ & 0.704 (NS) \\
\hline Median (range) & $28(20-40)$ & $28(20-39)$ & - & - \\
\hline \multicolumn{5}{|l|}{ Parity } \\
\hline Mean \pm SD & $2.04 \pm 1.13$ & $2.08 \pm 1.02$ & $-0.450^{a)}$ & 0.653 (NS) \\
\hline Median (range) & $2(1-5)$ & $2(1-5)$ & - & - \\
\hline One $(n=38)$ & $22(57.9)$ & $16(42.1)$ & $1.676^{b)}$ & - \\
\hline Two $(n=32)$ & $14(43.8)$ & $18(56.2)$ & - & - \\
\hline Three $(n=19)$ & $10(52.6)$ & $9(47.4)$ & - & - \\
\hline Four $(n=8)$ & $4(50.0)$ & $4(50.0)$ & - & - \\
\hline Five $(n=3)$ & $2(66.7)$ & $1(33.3)$ & - & - \\
\hline \multicolumn{5}{|l|}{ Abortion } \\
\hline Mean $\pm S D$ & $0.71 \pm 0.91$ & $0.60 \pm 0.84$ & $-0.514^{a)}$ & 0.598 (NS) \\
\hline
\end{tabular}

Values are presented as number (\%) unless otherwise indicated.

IUCD, intrauterine contraceptive device; Sig., significance; SD, standard deviation; NS, non significant.

${ }^{a}$ Mann-Whitney $U$ test; ${ }^{b}$ chi-square test, statistical significance was set at $P<0.05$. 


\section{Obstetrics \& Gynecology Science}

Vol. 64, No. 3, 2021

Table 2. Comparison between women without and with heavy menstrual bleeding associated with IUCD regarding ultrasound and color Doppler measurements before IUCD insertion

\begin{tabular}{|c|c|c|c|c|}
\hline \multirow{2}{*}{$\begin{array}{l}\text { Ultrasound and color Doppler measure- } \\
\text { ments before IUCD insertion }\end{array}$} & \multicolumn{2}{|c|}{ IUCD-related heavy menstrual bleeding } & \multirow{2}{*}{ Test $^{\text {a) }}$} & \multirow{2}{*}{ P-value (Sig.) } \\
\hline & Absent $(n=52)$ & Present $(n=48)$ & & \\
\hline \multicolumn{5}{|l|}{ Uterine length $(\mathrm{cm})$} \\
\hline Mean $\pm S D$ & $8.01 \pm 0.79$ & $7.98 \pm 0.94$ & -0.187 & 0.852 (NS) \\
\hline Median (range) & $7.95(7-9.80)$ & $7.60(5.90-10)$ & & \\
\hline \multicolumn{5}{|l|}{ Uterine width $(\mathrm{cm})$} \\
\hline Mean $\pm S D$ & $4.95 \pm 0.54$ & $5.12 \pm 0.70$ & -1.077 & 0.281 (NS) \\
\hline Median (range) & $4.95(4.20-6)$ & $5(4.10-8)$ & & \\
\hline \multicolumn{5}{|l|}{ Endometrial thickness (mm) } \\
\hline Mean $\pm S D$ & $5.70 \pm 0.36$ & $6.39 \pm 1.00$ & -4.772 & $<0.001(\mathrm{HS})$ \\
\hline Median (range) & $5.87(5.16-6.24)$ & $6.16(5.13-9.45)$ & & \\
\hline \multicolumn{5}{|l|}{$\mathrm{RI}$} \\
\hline Mean $\pm S D$ & $0.90 \pm 0.05$ & $0.78 \pm 0.05$ & -7.785 & $<0.001(\mathrm{HS})$ \\
\hline Median (range) & $0.89(0.86-1.02)$ & $0.77(0.70-0.99)$ & & \\
\hline \multicolumn{5}{|l|}{$\mathrm{Pl}$} \\
\hline Mean $\pm S D$ & $2.35 \pm 0.12$ & $1.92 \pm 0.12$ & -8.143 & $<0.001(\mathrm{HS})$ \\
\hline Median (range) & $2.34(2.18-2.59)$ & $1.88(1.78-2.42)$ & & \\
\hline
\end{tabular}

IUCD, intrauterine contraceptive device; Sig., significance; SD, standard deviation; NS, non significant; HS, highly significant; RI, resistance index; Pl, pulsatility index.

${ }^{a)}$ Mann-Whitney $U$ test, statistical significance was set at $P<0.05$.

Table 3. Comparison between women without and with heavy menstrual bleeding associated with IUCD regarding ultrasound and color Doppler measurements three and six months after IUCD insertion

\begin{tabular}{|c|c|c|c|c|}
\hline \multirow{2}{*}{$\begin{array}{l}\text { Ultrasound and color Doppler measure- } \\
\text { ments } 3 \text { months after IUCD insertion }\end{array}$} & \multicolumn{2}{|c|}{$\begin{array}{l}\text { Heavy menstrual bleeding associated } \\
\text { with IUCD }\end{array}$} & \multirow[t]{2}{*}{ Test $^{a)}$} & \multirow[t]{2}{*}{$P$-value (Sig.) } \\
\hline & Absent $(n=52)$ & Present $(n=48)$ & & \\
\hline \multicolumn{5}{|l|}{$\mathrm{RI}$} \\
\hline Mean $\pm S D$ & $0.89 \pm 0.05$ & $0.74 \pm 0.06$ & -7.985 & $<0.001(\mathrm{HS})$ \\
\hline Median (range) & $0.87(0.84-0.98)$ & $0.73(0.65-0.98)$ & & \\
\hline \multicolumn{5}{|l|}{$\mathrm{PI}$} \\
\hline Mean \pm SD & $2.33 \pm 0.11$ & $1.86 \pm 0.12$ & -8.096 & $<0.001(\mathrm{HS})$ \\
\hline Median (range) & $2.33(2.15-2.57)$ & $1.83(1.74-2.41)$ & & \\
\hline \multirow{2}{*}{$\begin{array}{l}\text { Ultrasound and color Doppler measure- } \\
\text { ments } 6 \text { months after IUCD insertion }\end{array}$} & \multicolumn{2}{|c|}{ IUCD-related heavy menstrual bleeding } & \multirow{2}{*}{ Test $^{a)}$} & \multirow{2}{*}{ P-value (Sig.) } \\
\hline & Absent $(n=52)$ & Present $(n=48)$ & & \\
\hline \multicolumn{5}{|l|}{$\mathrm{Rl}$} \\
\hline Mean $\pm S D$ & $0.88 \pm 0.05$ & $0.70 \pm 0.06$ & -7.955 & $<0.001(\mathrm{HS})$ \\
\hline Median (range) & $0.87(0.83-0.98)$ & $0.69(0.62-0.98)$ & & \\
\hline \multicolumn{5}{|l|}{$\mathrm{Pl}$} \\
\hline Mean \pm SD & $2.39 \pm 0.23$ & $1.79 \pm 0.13$ & -8.138 & $<0.001(\mathrm{HS})$ \\
\hline Median (range) & $2.30(2.15-3)$ & $1.76(1.70-2.40)$ & & \\
\hline
\end{tabular}




\section{Obstetrics \& Gynecology Science}

Alaa Mohamed Attia, et al. Uterine artery Doppler

Table 4. Diagnostic performance of PI and RI before ICUD insertion as an indicator for the heavy menstrual bleeding associated with IUCD; ROC curve analyses

\begin{tabular}{|c|c|c|c|c|c|c|c|}
\hline Cut-off values & Sensitivity & Specificity & PPV (\%) & NPV & Accuracy & AUROC & $\begin{array}{c}P \text {-value } \\
(\text { Sig. })^{\text {a) }}\end{array}$ \\
\hline $\mathrm{Pl}(\leq 2.02)$ & 95.8 (85.7-99.5) & $100(93.2-100)$ & 100 & 96.3 (87-99) & $98(89.6-99.8)$ & $0.971(0.916-0.994)$ & $<0.001$ (HS) \\
\hline $\mathrm{RI}(\leq 0.83)$ & $93.8(82.8-98.7)$ & $100(93.2-100)$ & 100 & $94.5(85.3-98.1)$ & $97(88.2-86.5)$ & $0.949(0.885-0.983)$ & $<0.001$ (HS) \\
\hline
\end{tabular}

Values are presented as percent $(95 \% \mathrm{Cl})$ unless otherwise indicated.

$\mathrm{PI}$, pulsatility index; RI, resistance index; IUCD, intrauterine contraceptive device; ROC curve, receiver operating characteristic curve; PPV, positive predictive value; NPV, negative predictive value; AUROC, area under receiver operating characteristic curve; $95 \% \mathrm{Cl}, 95 \%$ confidence interval; Sig., significance; $\mathrm{HS}$, highly significant.

a) $P<0.05$.
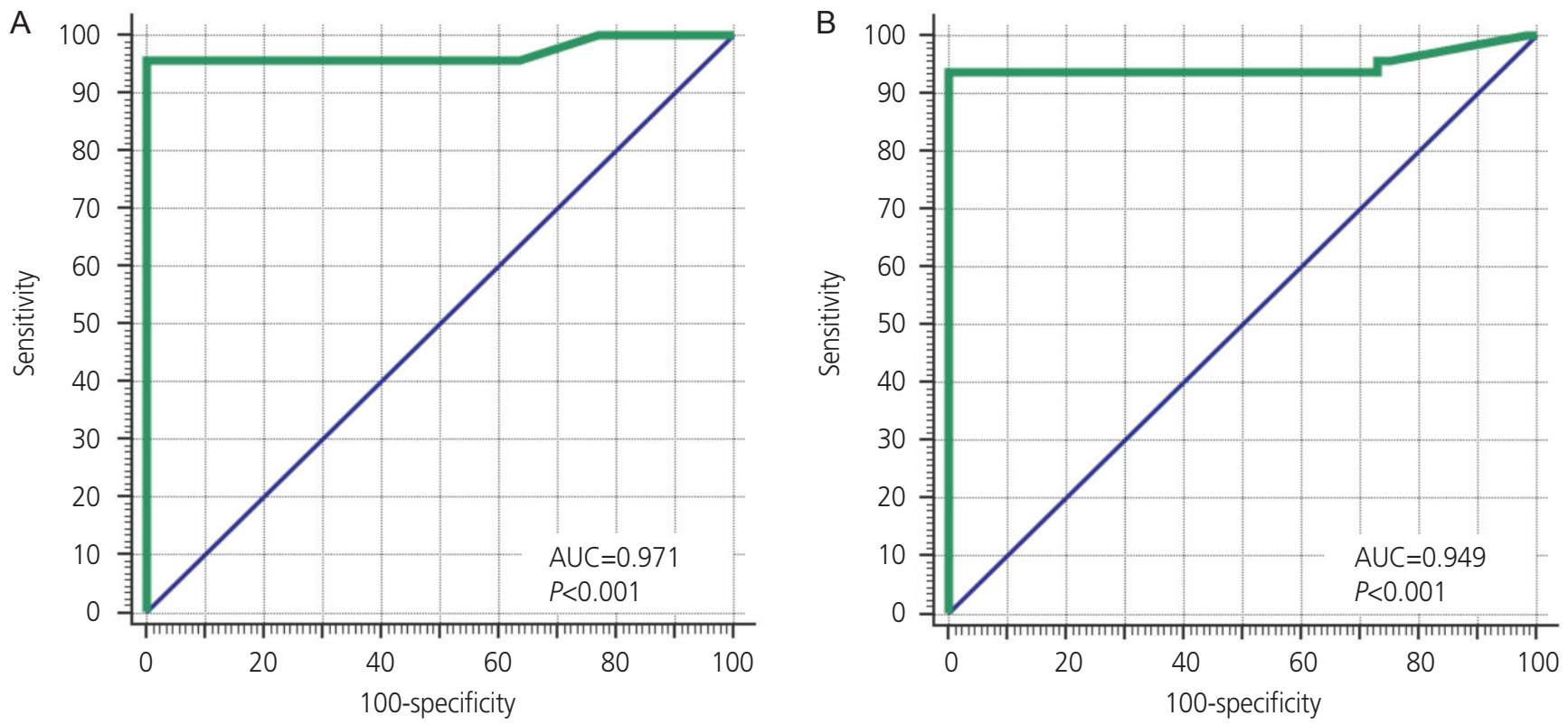

Fig. 1. Receiver operating characteristic curve of pulsatility index (A) and resistance index (B) before intrauterine contraceptive device (IUCD) insertion as a predictor for IUCD-related heavy menstrual bleeding. AUC, area below the curve.

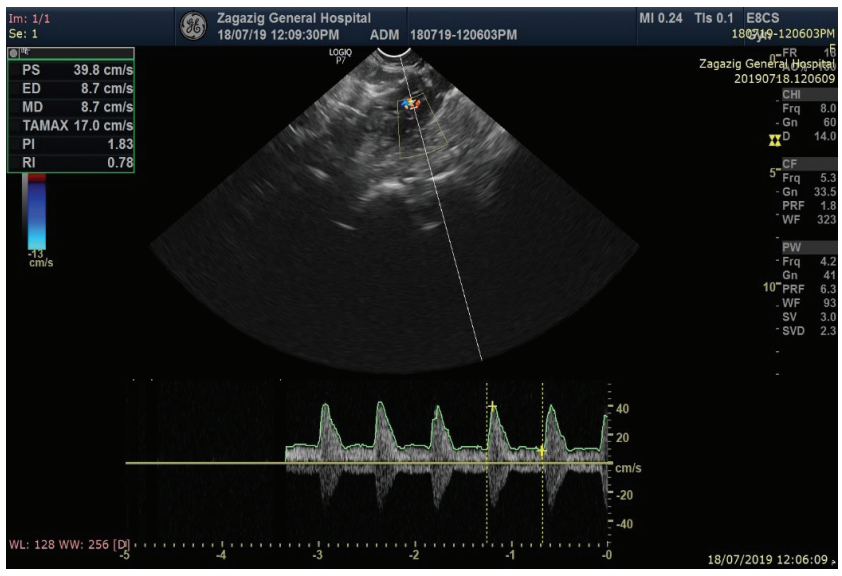

Fig. 2. Doppler indices of uterine artery (resistance index [RI] and pulsatility index $[\mathrm{PI}]$ ) and endometrial thickness in the bleeding group before the insertion.

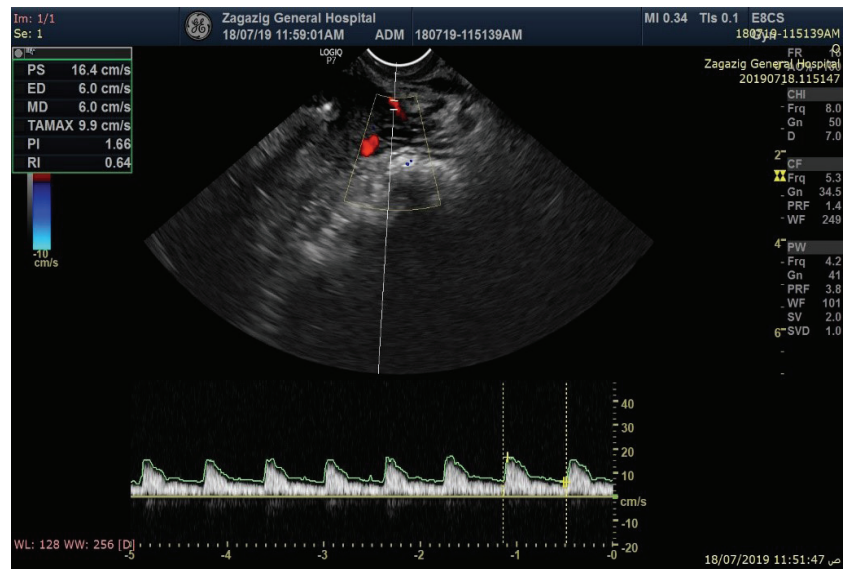

Fig. 3. Doppler indices of uterine artery (resistance index [RI] and pulsatility index $[\mathrm{PI}]$ ) and endometrial thickness of a patient in the bleeding group, three months after insertion. 


\section{Obstetrics \& Gynecology Science}

Vol. 64, No. 3, 2021

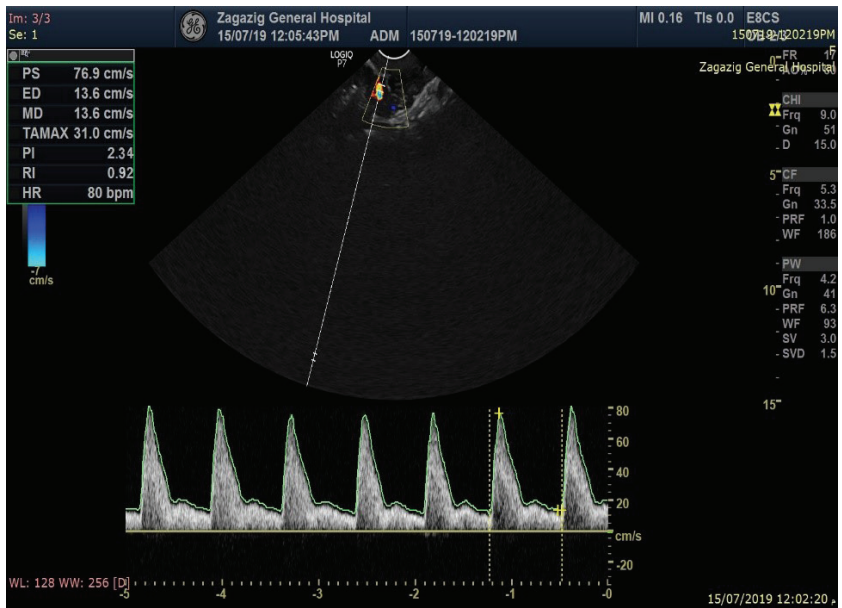

Fig. 4. Doppler indices of uterine artery (resistance index $[\mathrm{RI}]$ and pulsatility index $[\mathrm{PI}]$ ) and endometrial thickness in non-bleeding group, three months after insertion.

age use an IUCD. However, the distribution of IUCD users is remarkably inconsistent. In some countries, up to $40 \%$ of women use IUCD [7]. The mode of action of IUCD is not entirely known, but several theories have been developed that potentially explain the contraceptive effect of these devices by inhibition of implantation, inhibition of the development of the morula into a blastocyst, and progesterone antagonism [8].

The body-copper interaction prevents fertilization. As a consequence of the IUCD, infiltration of polymorphonuclear leukocytes occurs in the lumen of the uterus. The daily release of copper has been shown to equal $1 \%$ of copper administered orally per day. A cuprous complex is created from the chemical breakdown of cuprous oxide and saline, which generates cupric ions and free radicals. Metallic copper liquefies endometrial mucous membranes. Cupric ions enhance the biosynthesis of some prostaglandins, which explains the inhibition of implantation [7]. Although pre-and post-fertilization mechanisms may both contribute to the contraceptive effectiveness of IUCDs, research suggests that most of the effects occur pre-fertilization $[9,10]$.

Menstrual complications, pelvic pain, and dysmenorrhea are the most common adverse effects associated with the use of IUCD. Due to these side effects, approximately $10 \%$ of users have to remove their IUCD in the first year of use [11]. Among other factors, the latter has been due to changes in prostaglandin synthesis or uterine blood flow. However, none of these hypotheses are definitive. Doppler analysis of the uterine artery has been performed previously in women with increased menstrual flow after IUCD insertion [12].

Our clinical research aimed to study the relationship between heavy menstrual bleeding following IUCD insertion and the Doppler index of the uterine artery to protect women at risk of bleeding. The present study included 100 women who were divided according to the presence or absence of heavy menstrual bleeding into two groups: Group 1 $(n=52)$ included patients without menorrhagia, and Group 2 $(n=48)$, were women with menorrhagia. Transvaginal ultrasound and Doppler were performed three times: before insertion and three and six months after IUCD insertion.

Table 1 depicts the demographic data of the women who participated in the current study with a mean age of $28.01 \pm 5.51$ years, median of 28 years, and a range of 20-40 years, median 26 with range of (20-34). The mean parity was $2.04 \pm 1.13$, median was 2 , and the range was $1-5$. The mean abortion was $0.71 \pm 0.91$, median was 0 , and the range was $0-3$. Most cases had no history of abortion (57\%). There was no statistically significant difference between IUCD-related heavy menstrual bleeding and age, abortion, parity, and sonographic findings related to uterine size at the beginning of the study (Table 1).

In our study, we found a highly significant association $(P<0.001)$ between endometrial thickness and uterine artery Doppler indices (RI and PI) with IUCD-induced menorrhagia before insertion and after three and six months after IUCD insertion (Table 3,4). Our results are consistent with those of the latest studies $[7,13,14]$ that documented substantial changes in the endometrial thickness and the Doppler indices of the uterine artery (PI and RI) pre- and post-insertion of the IUCD.

Mohamed and Abdel Hakim [7] evaluated the PI and RI of the uterine artery after 90 days of IUCD insertion and reported a highly significant difference in endometrial thickness, $\mathrm{Pl}$, and $\mathrm{Rl}$ among women complaining of menorrhagia and those without. Fouda et al. [13] reported a significant reduction in $\mathrm{PI}$ and $\mathrm{RI}$ in the uterine artery in a group of women who complained of menorrhagia (group I) compared to women using Cu-IUD without uterine bleeding (group II) and women without CU-IUD (group III). In groups II and III, there was no statistically significant difference in $\mathrm{Pl}$ and RI. In another study of a group of women who complained of abnormal bleeding related to IUCD use, the uterine artery $\mathrm{PI}$ and RI levels have been considerably lower $(1.78 \pm 0.33$ 


\section{Obstetrics \& Gynecology Science}

Alaa Mohamed Attia, et al. Uterine artery Doppler

and $0.68 \pm 0.09$, respectively) than those without bleeding $(2.28 \pm 0.35$ and $0.87 \pm 0.13$, respectively) [14].

Järvelä et al. [15] stated the postulated mechanism that describes the relationship between low PI and RI in women who complained of menorrhagia. IUCD insertion causes an increase in the production of prostaglandins in the endometrium, which contributes to increased vascularity and vascular permeability, and inhibits platelet activation. These consequently increase menstrual bleeding.

Other earlier studies of the Doppler uterine artery showed contradictory findings. Rezk et al. [6] reported the absence of any significant difference in Doppler indices of the uterine artery (PI and RI) at three and six months following IUCD insertion in either group with or without IUCD-related heavy menstrual individually. Mutlu et al. [5] verified that there was no substantial difference in uterine blood flow among 120 participants who experienced an increase in menstrual bleeding, dyspareunia, or dysmenorrhea following the insertion of copper IUD when examined before insertion and six months after insertion. In addition, El-Mazny et al. [16] noticed that Doppler indices of the uterine artery, endometrial volume ( $P=0.303), \mathrm{PI}(P=0.699)$, and $\mathrm{RI}(P=0.788)$ were not significantly different between the two groups. Jiménez et al. [17] also examined uterine artery PI and RI prior to IUD insertion of the mid-luteal phase and 90 days post-insertion and found no significant variations in sub-endometrial vascularization in 27 patients who received LNG-IUS from 25 patients receiving $\mathrm{Cu}-\mathrm{T} 380 \mathrm{~A}$.

Regarding the ROC curve of PI and RI before CU-IUCD insertion (Fig. 4), we found that $\mathrm{PI} \leq 2.02$, and $\mathrm{RI} \leq 0.83$, correlated with heavy menstrual bleeding after insertion of IUCD, which is in accordance with previous results [6] (PI artery $<1.5$ and $\mathrm{Rl}<0.65, P$-value $<0.001)$ and Mansour et al. [14] (Pl artery $\leq 1.9$ and $\mathrm{RI} \leq 0.76, P$-value $<0.001)$. Mohamed and Abdel Hakim [7] demonstrated that both the uterine artery RI and PI have similar specificities in detecting menorrhagia after IUCD insertion. However, the uterine artery RI has greater sensitivity and better efficacy three months after IUCD insertion.

The results of our study revealed that the uterine artery Doppler indices (PI, RI) before insertion of the CU-T IUCD are lower in patients with heavy menstrual bleeding than in those who did not complain of heavy menstrual bleeding. Our findings confirmed our assumption that the initial use of TVUS with uterine artery Doppler studies may be useful as a predictor of the incidence of menorrhagia associated with IUCD insertion, which is a prime reason for IUCD withdrawal within the first year of use. The prediction should be carried out during the initial counseling of women who wish to use long-term reversible contraception. Another form of contraception should be considered for women with initially low values of the uterine artery indices, namely, PI and RI.

\section{Conflict of interest}

No potential conflict of interest relevant to this article was reported.

\section{Ethical approval}

The study was approved by the institutional review board (IRB) (IRB Number: ZU-IRB\#5037\#03/12/2018) and the Research Ethical Committee of the Faculty of Medicine.

\section{Patient consent}

The suggested study protocols were conveyed to all participants, verbal and written informed consent were obtained.

\section{Funding information}

None.

\section{References}

1. Thiery M. Intrauterine contraception: from silver ring to intrauterine contraceptive implant. Eur J Obstet Gynecol Reprod Biol 2000;90:145-52.

2. Lin X, Wei M, Li TC, Huang Q, Huang D, Zhou F, et al. A comparison of intrauterine balloon, intrauterine contraceptive device and hyaluronic acid gel in the prevention of adhesion reformation following hysteroscopic surgery for Asherman syndrome: a cohort study. Eur J Obstet Gynecol Reprod Biol 2013;170:512-6.

3. Stoddard A, McNicholas C, Peipert JF. Efficacy and 


\section{Obstetrics \& Gynecology Science}

Vol. 64, No. 3, 2021

safety of long-acting reversible contraception. Drugs 2011;71:969-80.

4. Fadiloglu S, Dilbaz B, Fadiloglu E, Dilbaz S. Relationship between copper IUD complications and ultrasonographic findings. Arch Gynecol Obstet 2018;297:989-96.

5. Mutlu I, Demir A, Mutlu MF. Can uterine artery Doppler parameters predict copper intrauterine device-induced side effects? Eur J Contracept Reprod Health Care 2013;19:51-6.

6. Rezk M, Elkelani O, Gaber W, Shawky M. Pre-insertion uterine artery Doppler indices may predict intrauterine contraceptive device-related heavy menstrual bleeding. Middle East Fertil Soc J 2018;23:496-500.

7. Mohamed RS, Abdel Hakim SF. Uterine artery doppler as predictor of side effects in copper intrauterine device users. Al-Azhar Assiut Med J 2015;13:63-71.

8. Larsson B. Reply to Drs. Salgo and Oster. Am J Obstet Gynecol 1977;128:921-2.

9. Gbarbea E. Contraception: past, present, and future [dissertation]. [Boston]: Boston University School of Medicine; 2015. 1-58.

10. Bioscientifica. Contraception: past, present, and future [Internet]. Bristol (UK): Bioscientifica; c2018 [cited 2018 May 10]. Available from: https://www.endocrineabstracts.org/ea/0056/ea0056pl1.htm.

11. Adeyemi-Fowode O, Bercaw-Pratt J. Intrauterine devices: effective contraception with noncontraceptive benefits for adolescents. J Pediatr Adolesc Gynecol 2019;32:S2-6.

12. Bousfield GR, May JV, Davis JS, Dias JA, Kumar TR. In vivo and in vitro impact of carbohydrate variation on human follicle-stimulating hormone function. Front Endocrinol (Lausanne) 2018;9:216.

13. Fouda UM, Yossef D, Gaafar HM. Uterine artery blood flow in patients with copper intrauterine device-induced abnormal uterine bleeding. Middle East Fertil Soc J 2010;15:168-73.

14. Mansour GM, Hussein SH, Mohammed HF, El Mekkawy SF, AkI SA, Abd El Dayem AA. Can we predict menorrhagia with intrauterine contraceptive device (IUCD) insertion? Open J Obstet Gynecol 2017;7:753-66.

15. Järvelä I, Tekay A, Jouppila P. The effects of a copperintrauterine device on the uterine artery blood flow in regularly menstruating women. Hum Reprod 1998;13:1841-5.

16. El-Mazny A, Abou-Salem N, Elshenoufy H. Threedimensional power Doppler study of endometrial and subendometrial microvascularization in women with intrauterine device-induced menorrhagia. Fertil Steril 2013;99:1912-57.

17. Jiménez MF, Arbo E, Vetori $D$, de Freitas FM, CunhaFilho JSL. The effect of the levonorgestrel-releasing intrauterine system and the copper intrauterine device on subendometrial microvascularization and uterine artery blood flow. Fertil Steril 2008;90:1574-8. 